\title{
Fitness knowledge, cardiorespiratory endurance and body composi- tion of high school students
}

\author{
Skip M. Williams ${ }^{1}$, Dan Phelps², Kelly R. Laurson ${ }^{1}$, David Q. Thomas ${ }^{1}$, Dale D. Brown ${ }^{1}$ \\ 1 Illinois State University, ${ }^{2}$ Hononegah High School, Illinois, USA
}

\section{Summary}

Study aim: The purpose of this study was to determine if high school physical education seniors' health-related fitness knowledge is related to their aerobic capacity and body composition.

Material and methods: The FitSmart test assessed students $(\mathrm{n}=171)$ health-related fitness knowledge. Aerobic capacity was calculated based on the students PACER score. Body Composition was measured using the Tanita TBF 300A body composition analyzer.

Results: Aerobic fitness was a statistically significant predictor of exam score $(\beta=0.563, p<0.001)$, but percent body fat was not $(\beta=0.185, \mathrm{p}=0.074)$. Comparing the health-related fitness exam scores by the FITNESSGRAM classification system, students who were classified as Very Lean and High Risk for body composition had lower exam scores than those classified in the healthy fitness zone.

Conclusions: The results confirmed previous findings that students have inadequate health-related fitness knowledge. Furthermore, the study extends these findings by identifying some associations of percent body fat and estimated $\mathrm{VO}_{2 \max }$ to health-related fitness knowledge.

\section{Key words: Adolescent - Cardiovascular Health - Physical Fitness - Physical Activity - Physical Education}

\section{Introduction}

Due to the increase in sedentary behavior [7] and obesity [20] among adolescents, public health initiatives (i.e. Comprehensive School Physical Activity Programs [3] and Healthy People 2020 [25]) have identified the school system, specifically the discipline of physical education, as a key contributor in helping educate youth in the adoption of a physically active lifestyle. The national standards for physical education have always supported this by identifying that students should demonstrate the knowledge and skills to achieve and maintain a healthenhancing level of physical activity (PA) and fitness [17].

Students can meet these goals by learning healthrelated fitness concepts, how to assess fitness, identify fitness goals, and design fitness programs. However, it has been identified that physical education programs need to be strengthened in regard to teaching health-related fitness $[11,14]$. Although the national standards for physical education identify the importance of promoting PA in physical education, physical education has been an underused source [8] and more efforts are needed in this field [21] to help reduce sedentary behaviors and obesity among adolescents.

To adopt a physically active lifestyle it is critical to understand (i.e. apply) the principles and concepts of health-related fitness [1]. The attainment of health-related fitness knowledge is positively related to PA participation $[12,25]$. Due to this relationship the mastery of healthrelated fitness concepts has emerged as an important area that needs to improve among adolescents $[15,19,22]$. The lack of health-related fitness knowledge has been linked as a factor to obesity among middle school youth [28]. Additionally it has been proposed that health-related fitness knowledge could be a contributing component to establishing and maintaining a physically active lifestyle [29]. There is limited research that has linked knowledge with achieving a health-enhancing level of physical fitness [17]. The purpose of this study was to determine if high school physical education seniors' health-related fitness knowledge is related to their aerobic capacity and body composition. A secondary purpose was to examine gender differences between health-related fitness, aerobic capacity, and body composition. 


\section{Material and Methods}

\section{Participants and Setting}

Participants were 171 senior physical education students from one public high school in the Midwestern U.S. Male $(\mathrm{n}=88)$ and female $(\mathrm{n}=83)$ participants (ages from 17 to 18 years) were assessed in 3 areas: health-related fitness knowledge, body composition, and cardiovascular endurance. Permission was obtained from the University Institutional Review Board, the school administration, teachers, and students prior to data collection.

\section{Instrumentation}

Health-related fitness knowledge was measured through a modified version of the FitSmart [29] healthrelated fitness knowledge exam. The FitSmart is the only validated standardized multiple choice exam designed to assess secondary students health-related fitness knowledge in the following areas: concepts of fitness, scientific principles of exercise, components of physical fitness, effects of exercise on chronic disease risk factors, exercise prescription and nutrition, injury prevention, and consumer issues [29]. Due to time constraints in the physical education setting the primary researchers modified the 50 question exam to 40 questions.

The FITNESSGRAM [9] 20-meter PACER (Progressive Aerobic Cardiovascular Endurance Run) test was used to assess aerobic capacity. The PACER is a multistage fitness test that progressively gets faster while the participant runs continuously back forth across a 20-meter space. Students' PACER scores were converted to $\mathrm{VO}_{2 \max }$ using the following formula: $\mathrm{VO}_{2 \max }=32.57+0.27$ (laps) +3.25 (gender) +0.03 (age) [5]. The PACER has demonstrated strong reliability and validity against measured $\mathrm{VO}_{2 \max }[9]$.

In a physical education setting there are three recommended methods to measure body composition (BMI, skinfolds and bioelectrical impedance (BIA)) [26]. These methods are recommended due to the feasibility (time and expense) of the assessment. In this study body composition was assessed using the Tanita TBF 300A BIA. There is some variability in results when comparing BIA to hydrostatic weighing, Bod Pod and Dexa. However, Terbizan, Rhee and Stasny [23] found that Tanita TBF 300A BIA provided accurate body fat percentage predictions. Procedures

Four certified high school teachers were trained by one of the researchers on how to administer the health-related fitness exam, body composition assessment (BIA), and the aerobic endurance assessment (PACER). Teachers were then given a 6-week timespan to complete the body composition and aerobic capacity assessments. Participant estimated $\mathrm{VO}_{2 \max }$ and percent body fat were categorized into the healthy fitness zones set by the FitnessGram/ ActivityGram Test Administration Manual [9]. The health- related fitness knowledge exam was completed during the 6th week. Participants completed the 40 question healthrelated fitness exam on a computer through an online survey system during their physical education class. Exams were then scored using the percentage of questions answered correctly.

\section{Statistical Analysis}

Descriptive statistics were calculated and stratified by sex. Independent samples t-tests (for continuous variables) and chi-square tests of independence (for categorical variables) were used to identify differences in fitness (body composition and aerobic capacity) and exam performance between males and females. Partial correlations were conducted to estimate associations between exam score, body composition and aerobic fitness while controlling for age and sex. Following, a multiple linear regression model was used to predict exam score from $\% \mathrm{BF}$ and estimated $\mathrm{VO}_{2 \max }$, also controlling for age and sex. Because both body composition and aerobic fitness are associated with FITNESSGRAM Healthy Fitness Zone (HFZ) standards, comparisons between the fitness groups (HFZ vs. high risk, etc.) were completed using univariate ANOVA models controlling for age and sex. Finally, to create groups of equal size, students were split into quartiles based on exam scores (Q1: $\geq$ $55 \%$, Q2: $45 \%$ to $<55 \%$, Q3: $38 \%$ to $<45 \%$, Q4: $<38 \%$ ). Continuous percent body fat and estimated $\mathrm{VO}_{2 \max }$ values were compared between quartiles using univariate ANOVA models controlling for age and sex. All analyses were conducted in IBM SPSS Version 20 (Somers, NY).

\section{Results}

Descriptive statistics are in Table 1 The partial correlations indicated a weak-moderate, negative relationship between $\% \mathrm{BF}$ and estimated $\mathrm{VO}_{2 \max }(\mathrm{r}=-0.44, \mathrm{p}<0.001)$. There was no association between $\% \mathrm{BF}$ and exam score ( $\mathrm{r}$ $=0.01, \mathrm{p}=0.916$ ). However, there was a weak association between estimated $\mathrm{VO}_{2 \max }$ and the exam $(\mathrm{r}=0.256, \mathrm{p}=$ 0.001), where students with higher exam scores tended to also have higher aerobic fitness when controlling for age and sex. When $\% \mathrm{BF}$ and estimated $\mathrm{VO}_{2 \max }$ were entered simultaneously into a multiple linear regression model similar results were found. Aerobic fitness $(\mathrm{ml} / \mathrm{kg} / \mathrm{min})$ was a statistically significant predictor of exam score $(\beta=$ $0.563, \mathrm{p}<0.001)$, but $\% \mathrm{BF}$ was not $(\beta=0.185, \mathrm{p}=0.074)$. The entire model, controlling for age and sex, accounted for $8.6 \%$ of the variance in exam score.

The results of the univariate ANOVA models comparing exam score by the FITNESSGRAM classification system are located in Table 2 For body composition, in general, exam scores were lower for students with $\% \mathrm{BF}$ values 
in the Very Lean and High Risk groups and highest in the HFZ and Some Risk stratifications. Considering only the significantly different groups, adjusted mean exam score differences ranged from approximately $5 \%$ to $7.5 \%$. When comparing the groups on aerobic fitness FITNESSGRAM classifications, the students in the HFZ had the highest adjusted exam score and the High Risk group had the lowest, but these differences were $1.5-2.0 \%$ and were not statistically significant.
The results of the univariate ANOVA models comparing continuous $\% \mathrm{BF}$ and $\mathrm{VO}_{2 \max }$ are located in Table 3. Because of ties within the exam score distribution, the four quartiles were similar in size, but not identical (varying between $20 \%$ and $29 \%$ of the total sample per group). There were no differences between the 4 groups by $\% \mathrm{BF}$ (all $\mathrm{p}>0.05$ ). However, the top quartile (highest exam scores) were those students with the highest adjusted mean estimated $\mathrm{VO}_{2 \max }$, by approximately $4-5 \mathrm{ml} / \mathrm{kg} / \mathrm{min}$.

Table 1. Aerobic fitness, body composition, and health-exam performance by sex

\begin{tabular}{lccc}
\hline Variable & $\begin{array}{c}\text { Males } \\
(\mathrm{n}=88)\end{array}$ & $\begin{array}{c}\text { Females } \\
(\mathrm{n}=83)\end{array}$ & $\begin{array}{c}\text { Combined } \\
(\mathrm{n}=171)\end{array}$ \\
\hline Age (years) & $17.3 \pm 0.5$ & $17.2 \pm 0.4$ & $17.3 \pm 0.4$ \\
Percent Body fat (\%) & $14.0 \pm 8.4$ & $24.7 \pm 9.2^{*}$ & $19.2 \pm 10.3$ \\
Percentage in Body Composition HFZ & $69.3 \%$ & $62.7 \%$ & $66.1 \%$ \\
Estimated $\mathrm{VO}_{2 \max }(\mathrm{ml} / \mathrm{kg} / \mathrm{min})$ & $52.8 \pm 7.2$ & $43.2 \pm 5.1^{*}$ & $48.2 \pm 7.9$ \\
Percentage in Aerobic Fitness HFZ & $88.6 \%$ & $78.3 \%$ & $83.6 \%$ \\
Exam Score & $45.0 \pm 11.0$ & $44.0 \pm 10.9$ & $44.6 \pm 11.0$ \\
\hline
\end{tabular}

Values are mean \pm SD, excluding percentages HFZ $=$ FITNESSGRAM Healthy Fitness Zone

*Significant difference between sexes $(\mathrm{p}<0.05)$

Table 2. Health-related Fitness exam score by FITNESSGRAM body composition and aerobic fitness standard classification

\begin{tabular}{lcc}
\hline Body Composition Classification & $\mathrm{n}(\%$ of sample) & Adjusted Mean Exam Score (SE) \\
\hline A) Very Lean & $25(14.6 \%)$ & $39.8 \pm 2.2 \mathrm{~B}, \mathrm{C}$ \\
B) Healthy Fitness Zone & $113(66.1 \%)$ & $45.7 \pm 1.0 \mathrm{~A}$ \\
C) Needs Improvement: Some Risk & $20(11.7 \%)$ & $47.2 \pm 2.4 \mathrm{~A}, \mathrm{D}$ \\
D) Needs Improvement: High Risk & $13(7.6 \%)$ & $39.5 \pm 3.0 \mathrm{C}$
\end{tabular}

\begin{tabular}{lcc} 
Aerobic Fitness Classification & $\mathrm{n}(\%$ of sample) & Adjusted Mean Exam Score (SE) \\
\hline A) Healthy Fitness Zone & $143(83.6 \%)$ & $44.8 \pm 0.9$ \\
B) Needs Improvement: Some Risk & $19(11.1 \%)$ & $43.5 \pm 2.6$ \\
C) Needs Improvement: High Risk & $9(5.2 \%)$ & $42.8 \pm 3.7$ \\
\hline
\end{tabular}

Means are adjusted for age and sex. Significantly different groups $(\mathrm{p}<0.05)$ are differentiated by superscript letters. For example, the A) Very Lean group adjusted exam score is significantly different from the Healthy Fitness Zone and Some Risk groups.

Table 3. Mean percent body fat and estimated maximal oxygen consumption by health-exam score quartiles

\begin{tabular}{lcccc}
\hline & $\begin{array}{c}\text { Quartile 1 } \\
(\mathrm{n}=48)\end{array}$ & $\begin{array}{c}\text { Quartile 2 } \\
(\mathrm{n}=49)\end{array}$ & $\begin{array}{c}\text { Quartile 3 } \\
(\mathrm{n}=34)\end{array}$ & $\begin{array}{c}\text { Quartile 4 } \\
(\mathrm{n}=40)\end{array}$ \\
Mean Exam Score & $57.4 \pm 4.1$ & $47.6 \pm 2.3$ & $40.1 \pm 2.0$ & $29.3 \pm 4.7$ \\
Adjusted Percent Body Fat $(\%)$ & $18.9 \pm 9.2$ & $19.9 \pm 10.8$ & $18.4 \pm 10.4$ & $19.4 \pm 11.2$ \\
Adjusted $\mathrm{VO}_{2 \max }(\mathrm{ml} / \mathrm{kg} / \mathrm{min})$ & $51.1 \pm 0.9^{*}$ & $47.1 \pm 0.9$ & $47.2 \pm 1.0$ & $46.6 \pm 1.0$ \\
\hline
\end{tabular}

*Significantly different from all other quartiles $(\mathrm{p}<0.05)$

Means (SE) are adjusted for age and sex, excluding exam score mean $\pm \mathrm{SD}$ 
In general males had a lower percent body fat and a higher estimated $\mathrm{VO}_{2 \max }$ than females. However, when using the age- and sex-specific FITNESSGRAM standards, a similar proportion of males and females tested into the HFZ. Further, the majority of students in the sample had body composition and aerobic fitness scores within the HFZ. Males and females also scored similarly on the exam, with a mean score near $45 \%$.

\section{Discussion}

Given the significant health consequences due to inactivity among adolescents, there is a need to examine factors that could potentially promote PA in obtaining adequate fitness levels. Knowledge acquisition of health-related fitness concepts has been identified as a factor that could potentially increase PA and fitness among adolescents. Over the past decade there has been a greater emphasis placed on physical education to teach health-related fitness concepts. The purpose of this study was to determine if high school physical education seniors' health-related fitness knowledge was related to their aerobic capacity and body composition. Although this is not the first study to examine health-related fitness knowledge it is the first to compare knowledge to two specific fitness outcomes. The average health-related fitness exam score among males and females $(44.6 \%)$ were a failing grade; however, the scores were comparable to other health-related fitness knowledge acquisition studies $[10,12,15,22,24]$ despite the methodological differences (different health-related fitness exams) between the studies. These failing scores can be attributed to the lack of health-related fitness content covered in class, teacher variables (i.e. knowledge, teaching style), and lack of student accountability (i.e. the grade on the exam does not count towards the students' overall grade). Only one aforementioned study [24] examined students' knowledge that were actually enrolled in a healthrelated fitness concept-based physical education class.

An examination of $\% \mathrm{BF}$ and estimated $\mathrm{VO}_{2 \max }$ among males and females showed that males had lower \%BF and higher estimated $\mathrm{VO}_{2 \max }$ scores $(14.0 \pm 9.4 \& 52.8 .6 \pm 7.2)$ than females $(24.7 \pm 9.2 \& 43.2 \pm 5.1)$. When $\% \mathrm{BF}$ and estimated $\mathrm{VO}_{2 \max }$ scores were placed in the FITNESSGRAM healthy fitness zones a slightly greater percentage of males $(69.3 \%)$ compared to females $(62.7 \%)$ were in the $\mathrm{HFZ}$ for $\% \mathrm{BF}$ and a greater percentage of males $(88.6 \%)$ compared to females $(78.3 \%)$ were in the HFZ for aerobic fitness. In a study measuring FITNESSGRAM achievement among Texas high school-aged youth $34.2 \%$ of males and $31.4 \%$ of females were classified in the HFZ for aerobic capacity and $70.6 \%$ of males and $70.0 \%$ of females were classified in the HFZ for body composition [27]. Although the body composition results were similar to the current study it should be noted that the aforementioned study assessed body composition through BMI measurement not $\% \mathrm{BF}$. The amount of individuals classified in the HFZ for aerobic capacity was significantly different than the current study. A possible explanation for this result could be that the participants in the current study had required daily physical education. The difference between the amount of males and females in this study that were classified in the HFZ for aerobic fitness was not a surprise. PA participation among females declines [4] dramatically between the ages of 12-18 years old. Due to this knowledge and previous research showing a moderate relationship between PA participation and aerobic fitness it was expected that more males than females would have been classified in the HFZ [13]. However, one must remember that there are many other factors besides PA participation that influences aerobic fitness such as age, genetics, developmental factors, body composition and motivation [18] that were not accounted for in the current study.

Despite the majority of the students failing the exam positive relationships did exist between exam scores, body composition and estimated $\mathrm{VO}_{2 \max }$ whether examining the data continuously or by grouping the data in the FITNESSGRAM health fitness zones. These relationships suggest that a by product of health-related fitness knowledge is healthy body composition and aerobic fitness. As this was the first study to compare HRF knowledge to aerobic fitness and body composition further research is needed among this population and elementary/junior high school students before these results can be generalized to other groups.

The implications of this study apply directly to physical education programs, teachers and physical education teacher preparation programs in the U.S. Physical education has been identified as a key setting to educate youth on health-related fitness concepts in hopes to reduce the obesity epidemic in the U.S. Although the results of this study show that the majority of students had good aerobic fitness and body composition the students demonstrated inadequate health-related fitness knowledge therefore cannot be deemed "physically educated". Responsibility to teach fitness knowledge falls on the PE teacher. It has been noted that Physical Education Teacher preparation programs at universities do not adequately train pre-service teachers in the area of health-related fitness [16]. Additionally, Castelli and Williams [6] identified that the main problem persists at the professional level because few physical education teachers participate in professional activities, such as attending conferences, reading professional journals, or participating in workshops that would provide current information regarding fitness knowledge [14]. Therefore if health-related fitness knowledge is important in sustaining and or adopting a healthy active lifestyle we need to hold the professionals in physical education accountable.

The limitations of this study are important to note. First, the students in this study may or may not have been 
enrolled in a PE class that taught health-related fitness concepts or had a teacher who addressed these concepts. A conceptually based PE course has been found to increase student knowledge [2]. Second, the exam was not part of their overall grade, some students might not have taken the exam seriously. Lastly, no other factors such as PA levels motivation or parental influence were accounted for. Exploring these additional variables might have given more insight to why the sample had adequate \%BF and estimated $\mathrm{VO}_{2 \max }$ and inadequate HRF knowledge.

This was the first study to compare $\% \mathrm{BF}$ and estimated $\mathrm{VO}_{2 \max }$ to health-related fitness knowledge. The results confirmed previous findings that students have inadequate HRF knowledge. Furthermore the study extends these findings by identifying some associations of $\% \mathrm{BF}$ and estimated $\mathrm{VO}_{2 \mathrm{ma}} \mathrm{x}$ to HRF knowledge. The results underscore that more efforts are needed to teach adolescents healthrelated fitness concepts and potentially mandating a concepts-based physical education course in schools.

\section{References}

1. Adams T.M., P. Brynteson (1992) A comparison of attitudes and exercise habits of alumni from colleges with varying degrees of physical activity programs. Res. Q. Exerc. Sport., 63(2):148-152. 2. Adams T.M., M.M. Graves, H.J. Adams (2006) The effectiveness of a university level conceptually based health-related fitness course on health-related fitness knowledge. The Phys. Educator., 63(2):104-112.

3. American Alliance for Health, Physical Education, Recreation and Dance. (2013). Comprehensive school physical activity programs: Helping students achieve 60 minutes of physical activity each day [Position statement]. Reston, VA: Author.

4. Bengoechea E., C. Sabiston, C. Ahmed, M. Farnoush (2010)

Exploring links to unorganized and organized physical activity during adolescence: The role of gender, socioeconomic status, weight status, and enjoyment of physical education. Res. $Q$. Exerc. Sport., 81(1):7-16.

5. Boiarskaia E.A., M.S. Boscolo, W. Zhu, M.T. Mahar (2011) Cross-Validation of an Equating Method Linking Aerobic FITNESSGRAM Field Tests. Am. J. Preventive Med., 41:124-130.

6. Castelli D., L. Williams (2007) Health-related fitness and physical education teachers' content knowledge. JTPE., 26:3-19.

7. Centers for Disease Control and Prevention (2010) Youth Risk Behavior Survey. www.cdc.gov/yrbs. Accessed August 8, 2012.

8.Cone S.L. (2004) Pay me now or pay me later: 10 years later and have we seen any change? JTPE., 23:271-280.

9.Cooper Institute (2010) FITNESSGRAM /ACTIVITYGRAM Test Administration Manual. Champaign, IL: Human Kinetics.

10. Desmond S.M., J.H.Price, R.S. Lock, D. Smith, P.W. Stewart (1990) Urban black and white adolescents' physical fitness status and perceptions of exercise. J. Sch. Health., 60(5):220-226.

11. Ferguson R., X. Keating, D. Bridges, J. Guan, C. Li (2007) California Secondary School Physical Education Teachers' Attitudes Toward the Mandated Use of the Fitnessgram. JTPE., 26(2):161-176

12. Keating X.D., L. Chen, J. Guan, L. Harrison, B. Dauenhauer (2009) Urban minority ninth-grade students health-related fitness knowledge. Res. Q. Exerc. Sport., 80(4):747-755.
13. Kolle K., L.B. Steene-Johannessen, S.B. Andersen (2010) Objectively assessed physical activity and aerobic fitness in a population-based sample of Norwegian 9- and 15-year-olds. Scandinavian J. Med. \& Sci. in Sport., 20(1):1-7.

14. Kulinna P.H. (2004) Physical activity and HRF knowledge: How much 1-6 grade students know. International J. of P.E., 41(3):111-121.

15. Merkle D.G., D.F. Treagust (1993) Student knowledge of health and fitness concepts and its relation to locus control. Sch. Sci Math., 93:355-259.

16. Miller M.G., L. Housner (1998) A survey of helath-related physical fitness knowledge among preservice and inservice physical educators. The Phys. Educator., 55(4):176-186.

17. National Association for Sport and Physical Education (2013) National Standards and Grade-Level Outcomes for K-12 Physical Education. Reston, VA. Available at http://www.aahperd.org/naspe/standards/ nationalStandards/PEstandards.cfm. Accessed August 8, 2013.

18. National Association for Sport and Physical Education (2001) The Physical Best Teacher's Guide: Physical Education for Lifelong Fitness. Champaign, IL: Human Kinetics.

19. National Center for Chronic Disease Prevention and Health Promotion (2000) Promoting better health for young people through physical activity and sports: A report to the president from the secretary of health and human services and the secretary of education. Silver Spring, MD: CDC at Healthy Youth.

20. Ogden C.L., M.D. Carrol, B.K Kit, K.M. Flegal (2012)

Prevalence of obesity and trends in body mass index among US children and adolescents, 1999-2010. JAMA., 307(5):483-490.

21. Pate R.R., M.G. Davis, T.N. Robinson, E.J. Stone, T.L. McKenzie, J.C. Young (2006) Promoting physical activity in children and youth: A leadership role for school. Circulation., 114(11):1214-1224.

22. Stewart S., M. Mitchel (2003) Chapter 4: Instructional variables and student knowledge and conceptions of fitness. JTPE., 22:533-551.

23. Terbizan D., Y. Rhee, S. Stasny (2009) A comparison of different body composition assessment techniques. Missouri $J$. of HPERD., 19:104-11.

24. Thompson A., J.C. Hannon (2012) Health-related fitness knowledge and physical activity of high school students. The Phys. Educator., 69:71-88.

25. U.S. Department of Health and Human Services. Office of Disease Prevention and Health Promotion. Healthy People 2020. Washington, DC. Available at http://www.healthypeople.gov/2020/default.aspx. Accessed August 8, 20013.

26. Vehrs P., R. Hager (2006) Assessment in interpretation of body composition in physical education. JOPERD., 77(7):46-51.

27. Welk G.J., M.D. Meredith, M. Ihmels, C. Seeger (2010) Distribution of health-related physical fitness in texas youth: A demographic and geographic analysis. Res. Q. Exerc. Sport., 81(3):S6-S15.

28. Zapata L.B., C.A. Bryant, R.J. McDermott, J.A Hefelfinger (2008) Dietary and physical activity behaviors of middle school youth: The youth physical activity and nutrition survey. J. Sch. Health., 78(1):9-18.

29. Zhu W., M. Safrit, A. Cohen (1999) Fitsmart Test User Manual: High School Edition. Champaign, IL: Human Kinetics.

\section{Received 7.08.2013}

Accepted 18.10.2013

(c) University of Physical Education, Warsaw, Poland 